Revista de la red interuniversitaria de estudios sobre las literaturas rioplatenses contemporáneas en Francia

\title{
Carlos Liscano, Jorge Luis Borges y Macedonio Fernández : un triángulo de dos orillas
}

\section{Carina Blixen}

\section{(2) OpenEdition}

1 Journals

Edición electrónica

URL: http://journals.openedition.org/lirico/954

DOI: 10.4000/lirico.954

ISSN: 2262-8339

Editor

Réseau interuniversitaire d'étude des littératures contemporaines du Río de la Plata

Referencia electrónica

Carina Blixen, «Carlos Liscano, Jorge Luis Borges y Macedonio Fernández : un triángulo de dos orillas », Cuadernos LIRICO [En línea], 8 | 2013, Puesto en línea el 01 enero 2013, consultado el 02 mayo 2019 URL : http://journals.openedition.org/lirico/954; DOI : 10.4000/lirico.954

Este documento fue generado automáticamente el 2 mayo 2019.

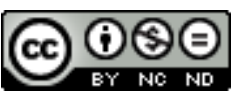

Cuadernos LIRICO está distribuido bajo una Licencia Creative Commons Atribución-NoComercialSinDerivar 4.0 Internacional. 


\title{
Carlos Liscano, Jorge Luis Borges y Macedonio Fernández : un triángulo de dos orillas
}

\author{
Carina Blixen
}

1 Carlos Liscano (Montevideo, 1949) estaba cursando la Escuela Militar de Aeronáutica cuando en 1970 fue arrestado durante tres meses. El Uruguay, gobernado por Jorge Pacheco Areco, vivía en « estado de excepción ». A comienzos de 1971 se integró al MLN, Movimiento de Liberación Nacional Tupamaros, grupo guerrillero fundado en los años sesenta. Fue arrestado de nuevo el 27 de mayo de 1972 y estuvo preso en el penal de Libertad ${ }^{1}$, una cárcel para presos políticos, hasta el fin de la dictadura cívico-militar que se impuso en Uruguay a partir del golpe de estado del 27 de junio de 1973 hasta 1985. En los primeros años leyó mucho y se dedicó a estudiar matemáticas; después contó que hacia 1980 tuvo que desistir porque no podía seguir avanzando solo. En enero de 1981, en una celda de castigo, de aislamiento total, que los presos llamaban la «Isla», creó mentalmente una novela que se llamó La mansión del tirano. Una vez salido de la «Isla », el $1^{\circ}$ de febrero de 1981, con lápiz y papel, a escondidas, se puso a escribir la novela así concebida. Años después pensó que más que el inicio de una narración, la fecha marcaba el nacimiento de un escritor. A partir de la publicación de La mansión del tirano en 1992 y de la reflexión sobre "el escritor y el otro", comenzada en Brecha en 1993, el narrador volverá una y otra vez a ese momento fundacional. A la novela primera se la llevó un soldado que requisó la celda de Liscano en febrero de 1982. Dos años después la volvió a escribir ${ }^{2}$.

2 La edición de Manuscritos de la cárcel ${ }^{3}$ reúne casi toda la obra de Liscano escrita en prisión: «Diario de la cárcel », «La mansión del tirano », « La edad de la prosa », « El método y otros juguetes carcelarios ", "El juego de la letra cambiada", "Los siete mensajeros (fragmentos)», «Apuntes: la literatura y la política» (fragmentos). Falta el libro de poesía: «¿Estará no más cargada de futuro?». Es una literatura de imaginación desbordante y abstracta que elude la prisión y sus circunstancias como tema aunque 
puede descubrirse una « poética del encierro » en diversos niveles de sus textos ${ }^{4}$. El título "Apuntes: la literatura y la política» reúne parte de los libros que Liscano leyó, seleccionó, transcribió, transformó en la cárcel ${ }^{5}$. La lista es muy amplia. Me interesa señalar en este momento solamente que, desde el comienzo, algunos de los escritores ahí reunidos actuaron como persistentes modelos de escritura. Samuel Beckett, Franz Kafka, Dino Buzzati, Juan Carlos Onetti y Louis-Ferdinand Céline (Viaje al fin de la noche) constituyen el núcleo íntimo fundador más intenso.

3 Hay catorce obras de Jorge Luis Borges en el catálogo de la Biblioteca del Penal de Libertad y un tomo de Obras Completas. De Macedonio Fernández figura Adriana Buenos Aires, Papeles de Recienvenido y un volumen de Cuentos/Miscelánea. Además de las obras de la biblioteca de la cárcel, los presos leyeron otras obras que les llevaban sus familiares. Liscano leyó en prisión No toda es vigilia la de los ojos abiertos de Macedonio. Le pregunté, por mail, si había leído a Macedonio en la cárcel ; respondió afirmativamente y contó, además, que llegó a Macedonio a través de Borges y Cortázar y que con Macedonio y Raymond Queneau aprendió que la literatura no tenía por qué referirse a la realidad.

La prisión condicionó su forma de leer, no solo por el acceso a los materiales : los muros de la cárcel preservaron al lector voraz de la vida literaria, de sus conflictos y de los juicios de sus posibles pares. Esos muros le permitieron un contacto con los autores leídos desasido de las líneas de opinión que orientan la lectura. Borges era una imagen pública irritante para los intelectuales rioplatenses de izquierda de los años sesenta y setenta. Liscano leyó de otra manera, aunque tal vez no fuera absolutamente sordo al ruido que produjo la contienda sobre el compromiso del escritor. Preguntado hoy por la lectura de Borges en la cárcel y por la posible perturbación de lo político, Liscano responde que no considera que deban mezclarse las ideas y la obra de los escritores. Sin embargo es posible pensar que, aunque sea involuntariamente, la reticencia a nombrar a Borges como una de sus lecturas fundadoras puede haber tenido que ver con la lucha ideológica presente en aquellos años.

5 La obra "Vida del cuervo blanco » de Liscano, publicada en francés y no en español ${ }^{6}$, vuelve visible la relación con los argentinos, en la medida en que reenvía explícitamente a ellos. Las obras de Borges y de Macedonio actuaron desde el comienzo en la conformación de su estética, pero a partir del libro citado las recupera en un diálogo público e íntimo al mismo tiempo.

6 «Vida del cuervo blanco $»^{7}$ está dividida en dos partes : La primera, titulada «El lector salteado », tiene un epígrafe de Macedonio Fernández: "Al lector salteado me acojo », frase tomada del Museo de la novela de la eterna ${ }^{8}$. «El lector salteado » es una narración estructurada en fragmentos numerados que escribe al mismo tiempo que «Vida del cuervo blanco». "Sigo con el cuervo. Releo (salteado) a Macedonio Fernández. Me divierto. Yo soy un lector salteado desde hace años» (fragmento 39). Y al final de «El lector salteado », refiriéndose al «trabajo » que se termina, apunta : « Me gusta llamarlo Lector salteado, como dice Macedonio Fernández, y que es como yo he sido » (fragmento 66).

7 La segunda parte, que da el título al libro, tiene dos epígrafes : uno es una cita de « Pierre Menard, autor del Quijote » de Jorge Luis Borges, otro una fábula de León Tolstoi sobre un cuervo que se pintó de blanco porque escuchó que las palomas comían bien; éstas lo descubrieron y lo rechazaron. Cuando volvió con los suyos, los cuervos no lo reconocieron y no lo aceptaron. En «Vida del cuervo blanco », el protagonista, un cuervo manchado de 
blanco, narra historias en el boliche del lugar. Una de las noches de tertulia se acuerda de su novia Carmencita con la que hizo giras por Europa con un espectáculo de canto :

Recuerdo especialmente una noche en Nîmes. Carmencita estuvo brillante, más que de costumbre. Después del espectáculo vino al camarín un escritor que quería saludarla. Era un viejito, natural de Nîmes. Traía un libro para regalarle. Don Pierre Menard le hizo una dedicatoria muy bonita. A mí me regaló una monografía sobre el Ars magna generalis del mallorquín, que no catalán, Ramón Lull. (p. 74)

El cuervo narrador hace como si contara cosas que le sucedieron y no distingue entre los personajes tomados de otros escritores (en este caso Pierre Menard del cuento de Borges) y los que son de su propia cosecha. Como en el juego de las cajas chinas, introduce en la cita de Borges la de Ramón Lull y alude (« mallorquín, que no catalán ») irónicamente a la pelea localista por la apropiación del autor. Gesto implícitamente ridiculizado en la concepción de la narración de Liscano. La referencia a Ramón Lull (1232-1315) no es casual. Aparece en el cuento de Borges : es solo uno de los puntos en la enumeración de lo que Menard dejó en su archivo particular ${ }^{9}$ y es una guiñada que el autor se hace a sí mismo y a los lectores que conocen sus obra. Filósofo, poeta, converso, Lull escribió Ars magna generalis cuando había decidido alejarse del mundanal ruido. El gesto del narrador que recibe el libro de Lull como regalo puede ser leído como un indicio que remite al libro de poesía de Liscano La sinuosa senda ${ }^{10} \mathrm{y}$ al deseo más o menos secreto y contradictorio, en la medida en que Liscano es un hombre público, de alejarse del mundo para pensar y escribir.

9 El cuervo entretiene a la concurrencia contando historias que son reescrituras de obras de la literatura universal, entre otras, la de Tarzán de Edgard Rice Borroughs, que en boca del cuervo pasa a llamarse Peteco. En la historia de "Peteco de los monos» está incrustada una escena que remite a la famosa del Quijote en la que el cura y el barbero hacen el escrutinio de la biblioteca de Alonso Quijano (I, 6). Peteco y un culto personaje llamado D'Arnot revisan la biblioteca que fue de Lord Greystoke: La lista es muy grande, en ella aparecen Pierre Menard y Macedonio Fernández: «Este es grande, Museo de la novela de la eterna» (p. 156), y un poco más adelante, Peteco le pregunta a Pablito (D’Arnot) : « ¿Somos personajes o no somos nada? Así como vamos ni el lector salteado nos aguanta (p. 159).

10 La emergencia de Borges y Macedonio Fernández en las últimas obras de Liscano tiene que ver con su elaboración más consciente de una estética de la reescritura y la lectura y con la búsqueda de una literatura que se acerque cada vez más a la elaboración del pensamiento. Es posible considerar que, a la manera de Macedonio Fernández o Felisberto Hernández, Liscano explora una manera de narrar pensando o de pensar narrando. La inversión de los términos quiere señalar la integración de narración y pensamiento en una forma propia, que se va transformando y que por momentos logra una atmósfera poética, gracias a la cadencia de la prosa y al efecto de las reiteraciones.

11 Más allá de la coincidencia en una estética de la lectura, Borges y Macedonio son modelos diferentes: Liscano reelabora a partir de cada uno de ellos formas e ideas específicas. Como Borges, Liscano es consciente de pertenecer y crear una tradición al escribir. Piensa que es necesario conocer las jugadas de los escritores admirados y no repetirlas. Así el escritor transforma el límite impuesto por la tradición (las jugadas ya realizadas) en productividad (el desafío de hacer algo distinto). En «El lector salteado » parece dar una idea más acotada de la libertad del escritor : « La creación consiste en elegir la tradición propia, encontrar allí las reglas que uno habrá de respetar y cumplirlas contra lo que sea. 
La libertad estaría en la elección de la tradición » (fragmento 16). Pero el escritor elige una tradición propia solo al crear una obra nueva, capaz de establecer una diferencia, y generar, así, una transformación de la tradición. Parafraseando a Borges: algunos escritores son capaces de crear a sus precursores.

El pasaje del artículo periodístico al libro de relatos o a la integración en un texto mayor, narrativo o ensayístico, es un movimiento frecuente en la obra de Liscano, que recuerda la forma de producción de Jorge Luis Borges : fragmentaria, contingente, en tránsito de un soporte a otro, a veces de un género a otro, que pone en evidencia, más que una noción de precariedad, la actitud de quien está escribiendo una literatura, no una serie de obras más o menos válidas en sí.

«El que escribe », publicado el 30 de abril de 1993 en Brecha, es el primer emergente de una manera de pensar en la creación que tuvo un momento de culminación en El escritor y el otro (2007) y que se continúa en la actualidad ${ }^{11}$. A la manera de Borges, también Liscano hace pequeñas introducciones a sus obras en las que informa, de manera precisa y sucinta, acerca de la procedencia de sus textos, además de hacer algunas reflexiones lacónicas. En la « Noticia » de El charlatán, publicado en 1994 en Uruguay mientras vivía en Suecia, da cuenta de su inseguridad ante la lengua y constata: «El que escribe es siempre un individuo. Libro tras libro el individuo presenta los mismos temas, las mismas preguntas, hasta quedar fijado a una única voz que todo lo cuenta $»^{12}$. En realidad, salvo la duda esencial por la existencia, formulada en variantes de "¿Qué hago yo aquí ?», las preguntas y los temas varían, pero la conciencia de la presencia del individuo irá derivando en una búsqueda formal que lleva a la autoficción. La primera persona no será entonces solo una voz, y no ha sido nunca « única ».

\section{La novela del regreso}

14 El capítulo «El inventado » de La ciudad de todos los vientos ${ }^{13}$ forma parte de la reflexión sobre « el que escribe «. En él está planteado el problema de la imposibilidad de ser el autor y el personaje al mismo tiempo, está formulada la afirmación de que la mayor creación del escritor es la invención de sí mismo como escritor, está establecida la exigencia de una ética de la escritura, la noción de ser « heredero de la maldición eterna de la palabra » y la voluntad de descartar la originalidad (2000, p. 135-138).

La ciudad de todos los vientos representa en el conjunto de la obra de Liscano un momento de transición: de crisis de una categoría (la ficción) y de iniciación en otra (la autoficción). Es la primera novela luego de la vuelta al Uruguay y también es la primera vez que aparece Montevideo en una obra narrativa del autor ${ }^{14}$. Es, en los sentidos señalados, inaugural, y es también una obra puente porque en ella el autor realiza el último intento (hasta ahora) de crear un universo de ficción como había hecho mientras vivió en Suecia. Por un lado, hay un proceso de autodescubrimiento del protagonista a través de una serie de escenas grotescas, oníricas o poéticas. Por otro, el anclaje textual en la figura del narrador (que remite al nombre del autor) hace que el relato dé cabida a reflexiones sobre la narración. Es el primer paso hacia una estética que reivindicará el contar sin asunto y que buscará la confluencia de pensamiento e imaginación.

16 Liscano la consideró en principio como una novela fallida, pues persistió años en la idea de volver a contar una historia como lo había hecho en El camino a Ítaca ${ }^{15}$. En el año 2007, 
comenzaba el ensayo «Del caos a la literatura » diciendo que hacía más de diez años que no escribía ficción :

Tal vez sea ésa la causa por la que la reflexión vuelve siempre al mismo punto: cómo empecé a escribir, por qué, qué me pasaba en aquel momento. Aunque no conozco el motivo siento que, si lograra entender cómo fue que llegué a la escritura creativa, podría volver a escribir ficción. ${ }^{16}$

17 La ciudad de todos los vientos se editó en el año 2000, después de una extensa labor de gestación, como la mayor parte de su obra. «Estocolmo-Barcelona-Montevideo / 1987-1999», dice la hoja final. En una libreta roja que se encuentra en el archivo de Liscano, una página escrita después de una anotación del 1.1.1995, encabezada « Para 'El novelista'" , registra una anotación que corresponde a La ciudad de todos los vientos. Este texto además de resultar muy útil para analizar el proceso de creación de la obra, que aquí no voy a realizar, señala desde el título desechado el eje de la narración. El fragmento titulado « El novelista » publicado en Oficio de ventriloquia $2^{17}$ parece sintetizar algunos aspectos del desarrollo de esta reflexión sobre la escritura : La voluntad de narrar genera la percepción de la infinita multiplicidad de lo real. Dicha multiplicidad paraliza la narración e incita al pensamiento, que no necesita de la escritura para realizarse.

La ciudad... está contada en primera persona por un narrador que recorre Montevideo en busca de asunto. Tiene la idea de hacer una novela « interesante ", « exótica », llena de color local o de magia como quieren los editores europeos, pero no logra inspirarse en la gris y lluviosa Montevideo, carente de indios y de accidentes naturales exuberantes. Es una crítica ácida a los epígonos del realismo mágico y a la aceptación de estereotipos. En un tono más sarcástico, su postura remite a la ironía de Borges en «El escritor argentino y la tradición » : «El culto argentino del color local es un reciente culto europeo que los nacionalistas deberían rechazar por foráneo $»^{18}$.

\section{El contar en escena}

En la última etapa de la obra de Liscano, la voz en primera persona es la de alguien que escribe y reflexiona sobre lo que ha significado la literatura en su vida. Esto sucede en $\mathrm{El}$ escritor y el otro (2007), «El lector salteado y Vida del cuervo blanco » (2009), «El trabajo de contar », «El trabajo de recontar. Novela no escrita » (2012). El narrador va creando, ante los ojos del lector, una estética de la narración e indefectiblemente de la lectura, pues al mismo tiempo en que postula que lo más importante no son los personajes y la trama, pone en escena el acto de contar y crea, al mismo tiempo, un lector que, si sigue leyendo, es porque está preparado para no encontrar como única satisfacción a la historia bien hecha. En lugar de contar su vida, el narrador lee (interpreta) algunos acontecimientos de ella; proporciona al lector lo sucedido y su mirada del presente.

Dice el narrador de «El trabajo de contar » : «Estos que muestro son los hechos de mi vida, más o menos, algunos de ellos, los que inventa mi socio» (2011, p. 185). Parece una buena definición de la autoficción que es una categoría ambigua que obliga a considerar lo autobiográfico y la dimensión escindida, plural, incontrolable de todo acto enunciativo. Porque después de Freud y de Lacan, es decir de la conciencia de la división del sujeto y de la opacidad del lenguaje, es imposible casi enunciar sin preguntarse quién es el yo que habla, o, cuál de los yo habla en el momento de la enunciación.

21 Desde la década del setenta del siglo XX se ha ido debatiendo la noción de autoficción. No voy a hacer un recuento de las instancias por las que ha pasado esta reflexión, sino a 
tomar algunos rasgos que la mayoría de los críticos consideran como determinantes de esta modalidad narrativa. En las obras de Liscano que estoy considerando en este artículo, el nombre en la tapa del libro coincide en parte con el de la voz enunciativa (puede ser C, Carlos, Carlitos o Liscano), también son reconocibles algunos sucesos y un entorno referidos por el autor en entrevistas y dichos de otros. El narrador no cuenta su historia, se ancla en un presente y unas circunstancias reconocibles para pensar y exhibir su escritura. Esa autoexhibición no es ingenua ni confesional y se realiza a partir de una escena básica que se repite : alguien que escribe, alguien que intenta contar.

« El lector salteado » y « Vida del cuervo blanco » establecen una relación similar a la del diario escrito en la cárcel y « La edad de la prosa » 0 « No hay salida $»^{19}$ que dieron lugar, respectivamente, a las publicaciones "Diario de “El Informante" " (El lenguaje de la soledad, 2000) y «El Informante » (El Informante. Relatos, 1997). Escribía al mismo tiempo la obra de imaginación («La edad de la prosa » o « No hay salida » / «El Informante ») y la reflexión sobre el acto de escribirla (diario de la cárcel / « Diario de «El Informante »). Esa manera de concebir en forma paralela la creación y la reflexión sobre ella en lugar de reforzar la diferencia entre ambas, paradójicamente, tiende a anularla, porque hace visible de qué manera la narración está cargada de pensamiento y la reflexión necesita de la narración.

El narrador de «El lector salteado » señala que el texto es la zona nocturna de «Vida del cuervo blanco ", que es la diurna ${ }^{20}$. Ese tono nocturno relaciona a «El lector salteado" con la perspectiva trágica de El escritor y el otro. Ella surge de la doble conciencia de que escribir es una pérdida de vida y de que ya no es posible contar. El hombre sacrifica su vida para que el inventado escriba. La conciencia es una condena: «Porque toda vida tiene gracia hasta que uno empieza a mirarse al espejo » (2007: 93).

En «Vida del cuervo blanco » la figura central no es la del que escribe sino la del que cuenta. El cuervo manchado de blanco dice sus historias ante la clientela del boliche de la zona. Tal vez en ese deslizamiento se encuentre una explicación posible para el tono más festivo de la narración del cuervo. Es un aventurero que relata sus aventuras, una especie de Sherezade que conquista a su auditorio y posterga cuento a cuento su posible expulsión del grupo. El tono ligero elegido condiciona los textos parodiados. En « El lector salteado» el narrador dice que releyó «La colonia penitenciaria» de Kafka para recontarla en " Vida del cuervo blanco », pero no lo hizo por la densidad del tono.

«El lector salteado » $\mathrm{y}$ «El trabajo de contar » tienen una estructura narrativa similar : ambos suman fragmentos numerados. El tono de «El trabajo de contar» y el de « recontar » es más leve, pertenecen a la zona « diurna» de «Vida del cuervo blanco » ${ }^{21}$. El narrador logra un tono humorístico y ameno, por momentos delirante (cuando multiplica personajes y espacios siguiendo el libre juego de la imaginación) o poético (cuando a través del leitmotiv o del juego de variantes dice una emoción), que capta el fluir de esa sustancia inasible pero primordial que hace posible la vida de todos los días.

«Vida del cuervo blanco » y «El trabajo de recontar » están organizados en capítulos a la manera de La mansión del tirano. Los títulos, largos y explicativos, son cervantinos o martorellinos (por Joanot Martorell, el autor de Tirante el Blanco). El procedimiento es similar al que empleó Liscano al transformar, en sucesivas etapas, la segunda versión de «La mansión del tirano" (Manuscritos de la cárcel) en la edición impresa de 1992: los capítulos y sus títulos cortan la narración, anticipan sucesos, producen un distanciamiento irónico. 
escritor y el otro y en "El lector salteado ", Liscano recrea la misma escena : en la cárcel un oficial entraba a la celda sistemáticamente para insultarlo. Ante la no respuesta del preso, el oficial termina dictaminando que es como un « perro». Frente al insulto, el preso delira pensando que él vale y que es escritor («El lector salteado», fragmento 23). Liscano encontró la salvación en la cárcel con la invención de ese otro que escribe. El hecho tiene la trascendencia y el dramatismo de un nuevo nacimiento. La obra de Liscano vuelve una y otra vez a la división que hizo surgir al escritor. Es también un tópico literario que está melancólicamente desarrollado en « Borges y yo » de El hacedor ${ }^{22}$ :

Sería exagerado afirmar que nuestra relación es hostil ; yo vivo, yo me dejo vivir, para que Borges pueda tramar su literatura y esa literatura me justifica. Nada me cuesta confesar que ha logrado ciertas páginas válidas, pero esas páginas no me pueden salvar, quizá porque lo bueno ya no es de nadie, ni siquiera del otro, sino del lenguaje o de la tradición (50).

El crítico brasileño Selomar Claudio Borges anotó esta relación en su estudio sobre $\mathrm{El}$ escritor y el otro y señaló una diferencia importante :

Em «Borges y yo " se plasma a conflitiva relação entre o homem privado e o homem público (o escritor). Como no texto de Liscano, o de Borges também coincide como o uso do nome própio do escritor factual. A pequena diferença está em que no texto borgiano o outro é o escritor, enquanto que Liscano parece dar nova leitura à questão ao chamar de outro ao homem privado, talvez ao querer definir a submissão que este lhe deve ao escritor. ${ }^{23}$

El tono de «El lector salteado » parece más exasperado que el de Borges : « ¿quién de los dos se expresa ahora cuando el escritor que yo soy no puede escribir, el individuo o la voz inventada ? ¿Quién se equivoca?» (fragmento 20). Pero en el retorno, una y otra vez a ese origen, la violencia inicial se va atemperando. $\mathrm{El}$ « dejarse vivir» de Borges supone una aceptación más plácida de la existencia. La paradoja es evidente : Liscano es un hombre de acción que se sitúa en el lugar del escritor; Borges es un hombre de letras que en su mitología personal rinde culto a los héroes y que pone el eje en la vida.

\section{Reescribir}

Liscano empezó a escribir reescribiendo. Desde las transcripciones de los autores leídos en la cárcel reunidos bajo el título « Apuntes de literatura y política », en las que no puede dejar de transformar el texto que quiere conservar, a la escritura primera de La mansión del tirano que comienza reescribiendo la manera de formularse un teorema y continúa reapropiándose de la libertad para ensamblar historias, personajes, situaciones de Tirant lo Blanc de Joanot Martorell, una de las novelas que leyó en la cárcel, los caminos de la reescritura son variadísimos.

31 Pudo estar generada por el despojo de materiales : cuando el 14.2.82, en la cárcel, le fue requisada La mansión del tirano, la volvió a escribir entre el 12 de marzo y el 28 de setiembre de 1984 ; cuando le robaron la computadora en octubre de 2011, al digitalizar «El trabajo de contar », lo reescribió. De ahí surgió «El trabajo de recontar. Novela no escrita » (2012). Pero la reescritura es fundamentalmente una práctica y una concepción estética que se ejercita más allá de la necesidad surgida del arrebato. La reescritura es un trabajo de multiplicación infinito y una respuesta íntima, ajena a las interferencias del mundo exterior y, paradójicamente, aún a la materialidad de la escritura. La mansión del tirano, según el testimonio de Liscano, fue compuesta primero en su mente, y escrita después de haber salido de « la Isla ». Antes de ponerse a escribirla de nuevo, el narrador

Cuadernos LIRICO, 8 | 2013 
de «La edad de la prosa » o « No hay salida », el que escribe al mismo tiempo el diario de la cárcel, dice que tiene a la primera novela en la cabeza y que necesita reescribirla. La reescritura es un proceso interior que implica un no desligarse, un retomarse continuo, un reelaborarse en la repetición y la diferencia. Es el reconocimiento de algo que ya estaba que permite el agregado de algo nuevo. Es el proceso de devenir sujeto escribiendo.

Liscano reescribe conceptos tomados de la lógica (en La mansión del tirano), libros de otros autores (en Memorias de la guerra reciente) y su propia obra. Esta última modalidad se desarrolla con intensidad a partir de La ciudad de todos los vientos (2000). En esta novela vuelve, por ejemplo, a La mansión del tirano. Por un lado, a su condición inicial de novela mental : « el héroe habría continuado cinco minutos más la reflexión hasta convertirla en novela, una novela pensada y no escrita, pero novela al fin » (p. 21). Por otro lado, a su comienzo : «Yo la había empezado. Cuando la empecé no sabía para dónde iba. La frase, quiero decir, no yo. Yo voy a tomar el ómnibus » (p. 63). «Cuando no sé qué hacer tomo un ómnibus » (p. 85). Y repite la experiencia de ser conocido por alguien que el narrador no sabe quién es. En La ciudad de todos los vientos se trata de una mujer (p. 85). La actitud de no contestar del protagonista alude también a la escena del comienzo de El camino a Ítaca (1994), cuando Vladimir, acosado por la polaca que lo encuentra en el tren de regreso a Estocolmo, no contesta para mantenerla lejos.

En El camino a Ítaca el narrador reescribe, a lo largo de la novela, la escena de la fantasía de la cabaña de troncos narrada en El pozo de Juan Carlos Onetti. En La ciudad de todos los vientos, vuelve a ella y a su sentido.

Era la vida relatada en tercera persona. La comencé en Estocolmo. Inclusive conocía el capítulo final, Última Thule. Eso iba a significar la llegada definitiva de $\mathrm{C}$ a un sitio, a una isla, una cabaña, donde lo esperaba la cifra final de su inútil vida.

- El camino a Ítaca.

- Tal vez, pero de otro modo.

- Te copiás a vos mismo.

- No me importa. Y dejame hablar. La novela de C, o la vida de C, debería acabar algún día en una Última Thule, una especie de reino inalcanzable. (p. 129).

El camino a Ítaca es una ficción relatada en primera persona, no en tercera como dice el narrador de La ciudad de todos los vientos, pero quien narra, Vladimir, no tiene rastros del nombre del autor ni su historia, aunque sí puedan señalarse en él actitudes, pensamientos y experiencias propias de Liscano. La ciudad de todos los vientos muestra el proceso de despojamiento de la ficción. En La mansión del tirano el narrador creó a M y a Hans y sus "vidas inútiles». En La ciudad... se refiere a «la novela de C o la vida de C». Los personajes que funcionaban como alterego parecen ir desvaneciéndose para que al final quede la $\mathrm{C}$ de Carlos, que remite al nombre del autor al mismo tiempo en que lo esquiva.

\section{Los trabajos y los días}

«El trabajo de contar » $\mathrm{y}$ « de recontar » están precedidos por un epígrafe de Franz Kafka, un autor al que Liscano ha vuelto habitualmente. El fragmento elegido de Descripción de una lucha (1904) puede leerse como un manifiesto sobre el poder de la imaginación, pues el narrador exalta su omnipotencia como demiurgo : «Como me gustan los pinares, fui atravesando pinares, y como me gusta contemplar en silencio el cielo constelado, vi surgir lenta y tranquilamente las estrellas... ». "El trabajo de recontar » agrega otros dos epígrafes. El primero está tomado del prólogo de «El atormentador de sí mismo » de 
Terencio : «No se dice nada que ya no haya sido dicho ». Podría interpretarse como una justificación de la estética del plagio. El otro está extraído del Fedro de Platón : « Dos son las cualidades de este libro : mover a risa y dar al hombre prudente consejos para bien vivir » y parece anticipar una forma de la sabiduría desplegada por el relato.

Contar es un trabajo : el narrador lo refiere así al final de «El lector salteado $»^{24} \mathrm{y}$ las dos obras últimas lo dicen desde el título : «El trabajo de contar» « El trabajo de recontar. Novela no escrita». Paradójicamente, un espíritu de gozo se desprende de ellas. A contramano de lo que enuncia, el autor parece haberse liberado del «trabajo » de contar una historia y haberse quedado con el placer de contar libremente. En estas obras y " Vida del cuervo blanco " ya no está el peso de la lucha contra la imposibilidad de contar, fuerte en El escritor y el otro y «El lector salteado ", ahora la dificultad parece un aliciente. En «El trabajo de contar » y el « de recontar » el narrador se entrega, cada vez más, al juego de la imaginación y el recuerdo.

El procedimiento puesto en juego aparece dicho por el narrador : «El trabajo de recontar es más difícil que el de contar [...] Pero yo debía, a partir de aquellas historias recordadas, volver a elaborar otras» («El t.r.», p. 40). Las figuras y las situaciones resurgen sintetizadas, aludidas rápidamente o expandidas. Un relato anterior o el carácter de una figura pueden ampliarse al incrustar narraciones, opiniones o reflexiones a partir de un detalle. El movimiento es constante, pues en la reapropiación el narrador agrega personajes, escenas, problemas y cambia los tonos y las formas de narrar.

Integra a los personajes de su literatura figuras de su intimidad, recupera expresiones del lenguaje popular y alusiones a personalidades de la cultura uruguaya de los cincuenta o de principios de siglo ${ }^{25}$, al mismo tiempo en que acumula las referencias librescas. Algunas figuras aparecen transformadas por esta mirada diferente. «El trabajo de contar » introduce la figura del padre que era una imagen, íntima y misteriosa, en relatos anteriores $^{26}$. Ahora habla y parece que, al otorgarle la palabra, lo puede tratar con humor. El padre repite en tono sentencioso : «Nunca vas a llegar a ninguna parte » (2011, p. 185) $y$, en « El trabajo de recontar ", pronuncia sentencias en latín. La madre, aparece también en diálogo con el narrador que quiere que le digan Sapo (2011, p. 224). Ella quiere mantener el nombre (Carlitos, Carlos) que es el lazo con la infancia. No acepta los enmascaramientos del narrador.

Entre los personajes nuevos está La Carmeta, cuyo nombre alude a quien es pareja de Liscano, que aparece transfigurada en la Reina del Baile. Acompañada siempre por El Gallo Diurno en quien se puede descubrir a un amigo íntimo: son el símbolo de la fidelidad. Junto a la imagen del narrador con «piedritas en el bolsillo» forman una constelación irradiante y «benefactora » que vuelve como leitmotiv junto a la noche y el pájaro : nudos emocionales y poéticos de este mundo nuevo.

El recuento exhaustivo de los vínculos que establecen estos textos con la obra anterior y con la vida del autor excede el marco del presente trabajo. Quisiera dejar la idea de que el texto funciona como una red en movimiento. El conjunto comienza a parecerse a una Comedia humana sin ambición realista, que se despliega en los registros más diversos : de lo dramático a lo cómico, del expresionismo y el sarcasmo a un humor de lo cotidiano ${ }^{27}$. 


\section{Seguir contando}

41 En un tono trágico (El escritor y el otro, « El lector salteado »), leve (« El trabajo de contar », «de recontar», «Vida del cuervo blanco») o grotesco («El Tarumba»)? el narrador retoma personajes, temas y preocupaciones en un movimiento que parece no tener fin. Este efecto lo logra mediante la incorporación de personajes nuevos junto a los ya conocidos por los lectores de su obra. «El trabajo de recontar» (2012), el relato último, hace más visible la tarea de estar escribiendo una literatura que marcha al ritmo de la vida $^{28} \mathrm{y}$ tiene, inevitablemente, un final abierto.

Desde La ciudad de todos los vientos el narrador ha ido planteando el sentido y la pertinencia ética de contar. Creo que hay un matiz de diferencia importante entre lo que la voz enunciativa pregona (no tiene sentido contar) y el resultado. Aunque el narrador no crea ya en la posibilidad o el interés de armar una trama con desarrollo, personajes y ambiente apuesta a la fantasía y a las posibilidades de la invención. Aunque ostentosamente «copie» asuntos, argumentos y personajes, el impulso de la creación inunda las historias. Aunque diga que todo está dicho, sigue diciendo. La ironía es el recurso para conservar la lucidez y las ganas (tal vez vergonzantes) de contar una y otra vez.

El llegar a defender el derecho de no contar una historia en el sentido tradicional exigió un largo proceso de trabajo con la escritura. Es el escritor reconocido que ha probado que puede hacer ficción, que ha escrito teatro, ensayo y poesía, el que interpela a sus lectores preguntando para qué contar o haciendo alarde de su falta de voluntad para armar una trama.

Es posible rastrear en la obra anterior de Liscano el deseo inverso : el de contar todo. Slavoj Zizek plantea, desde una perspectiva lacaniana ${ }^{29}$, que la realidad como la verdad no es una totalidad y su representación es imposible. El deseo de contar todo parece un delirio de omnipotencia que pudo ser la fuente de la creación en la situación límite en la que esta surgió, pero que fue perdiendo su sentido a medida en que fue madurando el ejercicio de escribir.

En « El lector salteado » el narrador plantea una vez más la idea de que la literatura le permitió salir del delirio cuando estaba en prisión ${ }^{30}$ y coloca enseguida esa experiencia límite de la literatura en el pasado. En el ensayo "El lenguaje de la soledad "se había referido a la creación como « un viaje a los límites de la lengua » ${ }^{31} \mathrm{y}$ en «Del caos a la literatura » contó que en la cárcel vivió «la explosión de la lengua »" Quien escribe vuelve, gracias al orden que la escritura exige, del límite con la locura. La ambición imposible de contar todo fue dejando otras huellas en su obra. En el relato « Para sacar un caballo del agua ", escrito en 2001, plantea que para llegar a conocerse hay que hundirse y alcanzar «algo que no necesite palabras». Pero solo es posible conocerse mediante el lenguaje y este genera la división.

El aceptar la imposibilidad de contar todo encuentra expresión en el estatuto de la autoficción, pues presupone la parcialidad. Escribe en «El trabajo de contar»: "Yo cuento algo, un poco, la cosa se mueve. Porque uno no debe contarlo todo. Eso no es lo mío » (p. 185). Y en «El trabajo de recontar. Novela no escrita » : « Es mejor mentir antes que contar todo» (p. 21). El reconocimiento de ese límite se da junto a la experiencia del poder de creación de la palabra. El versículo bíblico : «En el principio era el Verbo, y el 
Verbo era con Dios, y el Verbo era Dios. Éste era en el principio con Dios. Todas las cosas por él fueron hechas» (Juan 1:1-3) parece la máxima de las narraciones sobre la imposibilidad de contar si se le saca la desmesura del paralelismo entre Dios y el narrador. No vale la pena o no tiene sentido sostener una historia con la lógica de los personajes y la trama, pero al mismo tiempo el narrador se transforma en un mago que puede hacer aparecer todos los mundos posibles. No Dios, sino algo humano y falible como un mago que tiene el poder de la invención al mismo tiempo en que pertenece al mundo del espectáculo o de los cumpleaños infantiles. La proliferación de nombres propios en la última obra de Liscano puede relevarse como una marca de esta efervescencia inventiva.

En la cárcel todos los presos recibieron un número. Liscano fue el detenido № 490 . Sacar el nombre era una manera de borrar la pertenencia, significaba entrar en un sistema abstracto en el que se trataba de hacer desaparecer al individuo y su historia. En « El Informante», el relato que viene de "La edad de la prosa », escrito en la cárcel, el narrador cuenta la experiencia de haber sido un número :

Pocos días después de haber sido instalado en la Sala de Observación me di cuenta de que me habían puesto un número. No sé en qué momento ocurrió lo del número porque no pude controlar bien mis momentos. Pero me pareció un poco cómico, un número. Había llegado el progreso. Cantidad y no solo cualidad, una pequeña revolución tecnológica (Oficio de ventriloquia 1, 2011, p. 173).

En la misma narración, la posibilidad de tener un nombre provisorio, creado en el momento, genera una forma de reconocimiento e intimidad. El preso escucha un golpe en la pared y la primera reacción es violenta. Ante una serie de golpes furiosos, la respuesta es el silencio. Se da cuenta de que la intención del otro puede ser la de comunicarse. Empieza un intercambio codificado y se ponen nombres : Cafuringa y Repepé (Oficio de ventriloquia 1, 2011, p. 188). El relato « La Treintaidós », publicado en El País cultural № 386 el 26.3.1997, plantea de qué manera el llegar a ser supone un trabajo de aceptación del nombre que uno no eligió :

Cuando uno nace le ponen un nombre y uno después vive toda la vida con ese nombre. Cuando uno nace uno todavía no es y el nombre es una palabra y la palabra ya hace rato que es. A medida que uno crece no tiene más remedio que ir ajustándose al nombre que le pusieron (Oficio de ventriloquia 2, 2011, p. 86).

El Tarumba, el narrador del relato homónimo, quiere decir siempre la verdad o siempre mentir y no puede ninguna de las dos cosas. Reflexiona sobre el lenguaje : "Árbol, nube, perro, ¿qué son? Valent no es un perro, sino mi perro. Si se le quita el nombre se lo despoja del Ser, de su bella unicidad, de su diferencia » (Oficio de ventriloquia 2, 2011, p. 170).

La proliferación de nombres (que parecen crear personajes) en las narraciones últimas de Liscano forma parte de un proceso de liberación de la fantasía a partir del reconocimiento de la unicidad de los seres y del desajuste del lenguaje para dar cuenta de esa singularidad.

\section{Elogio del plagio}

51 Liscano empezó a escribir "Vida del cuervo blanco » en el 2006. Un año después, la editorial Belfond publicó una traducción de la primera novela editada en Suecia: Souvenirs de la guerre récente $e^{33}$. En el prólogo, «Échapper au silence », el autor realiza una 
nueva reflexión sobre la escritura. Dice del relato «Los siete mensajeros » leído y estudiado en la cárcel :

Écrire, c'est faire comme le prince de Buzzati. Écrire, c'est partir pour nulle part. Écrire, c'est être toujours en marche, sans possibilité d'arriver quelque part, à une situation définie. Écrire, c'est être en suspension dans l'air (2007, p. 15) ${ }^{34}$.

El prólogo termina con un diálogo entre el escritor y el otro :

Pendant un temps je me suis plu à ressembler à Buzzati dans Le Désert des Tartares, et c'est pour cette raison que j'ai écrit Souvenirs de la guerre récente. Plus tard, je me suis plus à ressembler à Beckett dans Molloy et j'ai écrit un petit roman qui s'appelle Le Rapporteur. Plus tard encore, j'ai fait la même tentative avec Céline dans Voyage au bout de la nuit, et j'ai écrit La Route d'Ithaque. L'Autre me dit :

- Tu as passé ta vie à copier.

- J'ai passé ma vie à essayer d'écrire des livres qui ressemblent aux livres que

j'admire. Tout est dit, il ne faut pas se proposer d'être original. (p. 17)

El 28 de noviembre de 2008 apareció, en la contratapa de Brecha, «Elogio del plagio », recogido en Oficio de ventriloquia 2. Es un paso más en relación a la reflexión sobre «El libro que falta " (El País cultural, 7.9.2007) : ahora la idea es que ya todo está dicho y que en principio no falta nada. Para qué escribir, entonces, es la pregunta inevitable. Liscano argumenta a partir del conocimiento de la lengua : siempre hay algo anterior dicho o no dicho. Es imposible ser original porque una frase siempre depende de otra. Sin embargo, eso no impide que el sujeto hable.

Una idea en principio no literal del "plagio" ha sido legitimada como una de las posibilidades de la literatura. Lo ha hecho Borges al resaltar la insignificancia de la autoría y la pertenencia de las grandes obras a nadie o a la tradición. Lo ha hecho Liscano una y otra vez al declarar su admiración por algunas obras y autores que elige como modelos de escritura. Pero también aflora, en «Vida del cuervo blanco ", la noción de plagio en el sentido primero de trampa o delito, ligado, paradójicamente, a una noción de verosimilitud. La idea de plagio como delito supone un valor de verdad o de legalidad, en cambio la verosimilitud depende del ajuste de la historia a un criterio de género o del estatuto de la ficción. Un parroquiano de la taberna aburrido por un relato, tal vez demasiado extenso para quien busca entretenerse, sobre una leche derramada, le grita " plagiario » al cuervo narrador (p. 66). Para que la narración funcione es necesario que el lector, como decía Chesterton, esté dispuesto a suspender el descreimiento. Puede, en cualquier momento, dejar de hacerlo. El que grita « plagiario » y corta el acto de contar lo hace porque ya no cree más en la historia porque está aburrido o porque algo de la magia de la escucha no funcionó. Porque qué importancia tiene saber de quién es la historia. Más que referida a la mentira o la verdad, la acusación surge de una falla del poder seductor del relato.

El epígrafe extraído de « Pierre Menard, autor del Quijote » presente en « Vida del cuervo blanco " actúa de manera contradictoria. La posibilidad de entender que El Quijote de Menard es distinto del de Cervantes pasa entre otras consideraciones por la aceptación de una autoría diferente en un contexto que también lo es. Pero el cuervo no realiza una reescritura à l'identique como Menard, sino que juega a potenciar la significación de las variaciones. Si, en una reflexión por el absurdo, el colmo de la reescritura puede ser el logro de la identidad, el colmo del « lector salteado », puede ser transformar lo que se lee reescribiéndolo.

El epígrafe de Borges puede señalar otro aspecto de la actitud del lector. El lector del cuento de Borges puede no haber leído El Quijote, ¿podrá igualmente apreciar que 
"Menard (acaso sin quererlo) ha enriquecido mediante una técnica nueva el arte detenido y rudimentario de la lectura : la técnica del anacronismo deliberado y de las atribuciones erróneas " $?^{35}$. Aunque se pueda leer el cuento de Borges sin haber leído $\mathrm{El}$ Quijote, el lector podrá disfrutar del relato solo en la medida en que haya llegado a cierta sofisticación en su saber literario. La reivindicación del plagio implica el rechazo de la noción de originalidad. Algo « original» es a la vez propio, verdadero, nuevo. El Diccionario de la Real Academia Española establece nueve acepciones del adjetivo «original». La primera dice: «Perteneciente o relativo al origen ». La segunda y la sexta se refieren a la noción de novedad: "Que resulta de la inventiva de su autor " y "Que tiene, en sí o en sus obras o comportamiento, carácter de novedad». El plagiario acepta que no hay origen en el lenguaje ni en la literatura ni posibilidad de novedad en sentido absoluto ${ }^{36}$.

Para el escritor, elogiar el plagio es una forma de la humildad (que instaló Borges, con todas sus ambigüedades) surgida de la conciencia de formar parte de una serie. En la obra última ("Vida del cuervo blanco», "El trabajo de contar» y el de "recontar») va apareciendo la alegría de la gratuidad. Abandonar la necesidad de decir la verdad o de construir una historia que represente algún aspecto de la realidad refuerza, paradójicamente, el lazo entre la literatura y la vida, en la medida en que se acepta el acto de escribir en su dimensión cotidiana, no ya en guerra con la existencia sino como una posibilidad que la potencia.

El cuervo que cuenta en « Vida del cuervo blanco » es un narrador que remite al autor por ese trabajo de contar día a día (o noche a noche, mejor) ${ }^{37}$, por sus lecturas, por sus recuerdos y por su impostura. Pero ¿cuál es el límite de la autoficción? ¿Qué pasa con el efecto de identificación cuando el que narra es un cuervo ? Escribe el narrador de «El lector salteado »: «El cuervo es como yo, se cuenta historias para demostrarse que existe $»(\text { fragmento } 52)^{38}$.

Al suprimir o vaciar al máximo el enunciado, el relato, la trama, la estructura que permite al lector abandonarse en un mundo de ficción, el narrador queda enfrentado al lector y, en esa situación, se crea la figura del espejo o desdoblamiento : un escritor lector/un lector escritor.

Elogiar el plagio es una manera de aumentar las exigencias del lector y el escritor. El « copiar » asuntos pone en evidencia que ellos no son lo más importante y desplaza lo significativo hacia la variación, el lenguaje, la perspectiva. El lector «salteado» es el lector no domesticado, no « alucinado » por la intriga o los personajes, diría Macedonio, sino en relación libre, personal y exigente con aquello que lee. Aceptar la no verdad de la obra equivale para el lector a darse cuenta de su propia insustancialidad. Ése es el lector que las historias del cuervo exige. El narrador de « Vida del cuervo blanco » se considera un «lector salteado » y realiza, a la manera de Macedonio, una escritura " a la vista " ${ }^{39}$ : «Bien, hay que hacer lo que sea para continuar en camino. Ya me veo yo, por allá adelante, por la página cincuenta o en las inmediaciones, a lo lejos, un puntito en el sendero, el sujeto mintiendo todo el tiempo para poder avanzar » (p.4).

El lector es más libre en tanto es más consciente pero está más exigido en tanto debe comprometer todo su ser en la lectura. Es una estética que respeta al lector al ponerlo ante la dificultad de la comprensión y así ante la complejidad de su existencia, pero, al mismo tiempo, ejerce cierto despotismo al reclamarle una y otra vez un esfuerzo máximo. 
Julio Prieto se refiere al proyecto macedoniano de onirizar la realidad y su «irónica campaña presidencial de 1922/1927» :

No es casual la afición de Macedonio a auto-representarse en sus textos como « dictador ». Aparece, por ejemplo, como caudillo platónico en el título - „ El buen déspota » " de un texto publicado bajo el pseudónimo "Dionisio Buonapace» ( Papeles de Buenos Aires, $\mathrm{n}^{\circ} 5$, 1945) [...] La escritura de Macedonio emula una suerte de conspiración « dictatorial » que esclaviza al lector, aherrojándolo al « trabajo » de la lectura como a un pesadillesco, interminable « proceso (e) lectoral » : « lectura de trabajo : leerás más como un lento venir viniendo que como una llegada » (Relato 133)..$^{40}$

Hay un punto en que esta mayor libertad puede transformarse en sumisión, consentida, a esa voz que no cede su dominio. La primera novela de Liscano: La mansión del tirano planteaba en principio la «tiranía » del narrador hacia sus personajes y su historia, pero la omnipresencia del discurso del narrador, su volubilidad, anunciaba esta otra forma de tiranía hacia el lector. Desde el comienzo, el narrador de Liscano centró en sí mismo el hipnotismo que la narración ejerce sobre el lector. Sin embargo, creo que tiende más a "seducir » al lector que el narrador de Macedonio. Tampoco le cuenta una historia, pero lo interpela menos, le permite más dejarse ir siguiendo el ritmo del estilo o el sendero creado por el humor y la imaginación. El texto va surgiendo ante los ojos del lector, sin plan previo, estructura, ni « lógica » de los hechos o de los personajes, pero al mismo tiempo tiende una gran red de complicidades que envuelve a quien lee. Por otra parte, Macedonio preconiza el escribir " mal y pobre », y Liscano en cambio hace de la exactitud un rasgo sobresaliente de su estilo. Como ha señalado Julio Prieto, el « escribir mal » de Macedonio « no equivale a escribir espontáneamente », sino a desautorizar la gramática y el orden del lenguaje (p. 239). En Liscano se puede señalar un camino que va del caos a la buscada perfección lingüística. No participa del intento vanguardista de desestructurar el lenguaje, sino de un «trabajo » de precisión que, en la línea de Borges, se acerca más a la noción de lo clásico.

\section{La literatura como « surco »}

En «El lector salteado» el narrador describe una vez más el acto fundacional de su escritura : el momento en que decidió que sería escritor y concibió La mansión del tirano. Para hacerlo busca en el diccionario la palabra «delirar». Escribe que para Joan Corominas (Diccionario crítico-etimológico) , « delirar » viene del latín delirare, « apartarse del surco " (fragmento 34). En sus últimas obras, el narrador crea un fluir y una posibilidad de « dejarse ir », diferente al primero de La mansión del tirano, pues el « surco » de la literatura, el largo ejercicio, la sabiduría técnica y la parodia han alejado la escritura del desborde originario.

Si la palabra hermano trajo consigo la palabra gemelo es obligatorio continuar la historia a partir de esa dificultad. Porque la comodidad consistiría en borrar y recomenzar. La escritura impone existencias a partir de lo ya contado (« Vida del cuervo blanco ", p. 127).

La escritura acepta « el accidente » (la palabra « hermano » que trae a "gemelo »), algo incontrolable que surge, al mismo tiempo en que recupera la noción lógica de las restricciones: cada palabra establece un campo de lo posible. Ese juego entre lo imprevisto y la recuperación es el que quise mostrar en la comparación entre Liscano y los dos argentinos. Liscano « tenía » las lecturas de Borges y Macedonio, ambos formaban 
parte de su acervo, de sus recursos, del saber decantado de las lecturas de la cárcel. Los actualiza, de una manera particular, según sus nuevas necesidades, cuando « el trabajo de contar » le plantea desafíos imprevistos. Lo nuevo surge de lo conocido, guiado por el impulso de conocer y conocerse. El mismo movimiento interior alimenta la opción de escribir en una tradición y, en el momento de la producción de Liscano que he analizado, establece como « precursores » a Macedonio Fernández y a Jorge Luis Borges.

\section{NOTAS}

1. Así se llama porque está al lado de una ciudad llamada Libertad. La ironía es involuntaria.

2. La mansión del tirano fue publicada por primera vez en Montevideo, Arca, 1992. Fue reeditada, con anotaciones del autor, en Montevideo, Argumento, 2011.

3. C. Liscano, Manuscritos de la cárcel, edición y coordinación Fatiha Idmhand, Montevideo, Ediciones del caballo perdido, 2010.

4. Oscar Brando plantea el tema de la « poética del encierro » en «Carlos Liscano : La poética de la soledad ", Montevideo, Deslindes. Revista de la Biblioteca Nacional 2-3, Montevideo, mayo 1993.

5. La edición de los Manuscritos apenas da cuenta de esas lecturas que pueden consultarse en la página web preparada por Fatiha Idmhand : http://manuscritsentredeux.recherche.univ-lille3.fr 6. C. Liscano, Le lecteur inconstant suivi de Vie du corbeau blanc, Paris, Belfond, 2011. Traducción de Martine Breuer y Jean-Marie Saint-Lu.

7. «Vida del cuervo blanco » tiene 179 páginas, las primeras 56 corresponden a «El lector salteado", las que restan a «Vida del cuervo blanco». Como «El lector salteado» está organizado en fragmentos numerados; lo cito por fragmentos, así se puede seguir también en la traducción. A « Vida del cuervo blanco », por páginas.

8. M. Fernández, Museo de la novela de la eterna. Selección, prólogo y cronología de César Fernández Moreno, Caracas, Biblioteca Ayacucho, 1982, p. 262.

9. Es el punto « $\mathrm{f}$ » de una lista alfabética que llega hasta la « $\mathrm{s}$ » : « Una monografía sobre el Ars magna generalis de Ramón Lull (Nîmes, 1906) ». J.L.Borges, Ficciones, Buenos Aires, Emecé Editores, 1956, p. 46.

10. C. Liscano, La sinuosa senda, Montevideo, Ediciones del caballo perdido, 2002.

11. «El que escribe» fue recogido en El Informante, Montevideo, Trilce, 1997, y en Oficio de ventriloquia 1, Montevideo, Planeta, 2011.

12. C. Liscano, El charlatán, Montevideo, Cal y Canto, 1994. La noticia introductoria está fechada en 1993 (Estocolmo).

13. C. Liscano, La ciudad de todos los vientos, Montevideo, Planeta, 2000.

14. En la versión de La mansión del tirano recogida en Manuscritos de la cárcel (2010) aparece reiteradamente mencionada La Teja, el barrio de Montevideo donde nació Liscano. Esas menciones desaparecen en la edición de la novela de 1992.

15. C. Liscano, El camino a Ítaca, Montevideo, Cal y canto, 1994.

16. C. Liscano, « Del caos a la literatura », en Trazas y Ficciones. Literatura y psicoanálisis, Asociación Psicoanalítica del Uruguay, Biblioteca uruguaya de psicoanálisis, vol. VII, Montevideo, noviembre 2007.

17. C. Liscano, Oficio de ventriloquia 2, Montevideo, Planeta, 2011, p. 58.

18. J.L. Borges, Discusión, Buenos Aires, Emecé, 1964, p. 156. 
19. «La edad de la prosa " $\mathrm{y}$ " No hay salida » son dos maneras diferentes que tuvo el autor de referirse a la misma obra. En los Manuscritos de la cárcel (2010) figura con el primer título.

20. Escribe en «El lector salteado » : «Vida del cuervo blanco es mi parte diurna. Esto que aquí escribo es cosa de la noche » (fragmento 52).

21. En «El lector salteado » dice de «El trabajo de contar »: «Es el viejo sueño de escribir sobre nada como las conversaciones intrascendentes en reuniones de amigos» (fragmento 62).

22. J.L. Borges, El hacedor, Buenos Aires, Emecé, 1960.

23. S.C. Borges, Performance autoral e problematização da escrita em El escritor y el otro de Carlos Liscano, Florianópolis, Universidade Federal de Santa Catarina, 2012. Dirección de tesis de maestría : Liliana Reales, p. 95.

24. «Enero de 2010. Ayer terminé Vida del cuervo blanco. Hoy doy por terminado este trabajo " (fragmento 66).

25. El « chiquitifliqui » que pide el narrador de estas historias es una referencia a Dante Ortiz, una personalidad de la radio de los años cincuenta. Las alusiones a Carlos Gardel son constantes.

26. El padre había aparecido en el relato «Agua estancada «(Agua estancada y otras historias, Montevideo, Arca, 1990) y en El furgón de los locos, Montevideo, Planeta, 2001.

27. A vía de ejemplo : la guiñada que se repite a lo largo de « Vida del cuervo blanco ». El cuervo tuvo una peluquería en Paris, Le Montevidéen, en el 490 de la rue Delambre (p. 73). Sintetiza la admiración por el autor de Los cantos de Maldoror, el Conde de Lautréamont, el número que Liscano tuvo en la cárcel y crea un nombre con lo que puede ser una descripción de la situación de los escritores exilados o migrados en Paris (tienen hambre).

28. Dice el narrador : « ¿por qué llegar si se puede seguir en marcha, otro tramo, otra página? «(« El t.r.», p. 254)

29. S.Zizek, «La violence entre fiction et fantasme. Vers une théorie lacanienne de l'idéologie », en L'Atelier: Hors Série des Carnets de Lille, 1995-1996 : "pour qu'émerge (ce que nous éprouvons comme) la "réalité ", il faut que quelque chose en soit forclose, c'est-à-dire que la "réalité ", comme la vérité, n'est jamais “toute”. Ce que cache le spectre n'est pas la réalité mais son “refoulé primordial ", le x irreprésentable sur lequel se fonde la réalité elle-même » (p. 84).

30. " Escribir era como el viaje de regreso del país de los locos ». « Tal vez sea eso lo que hoy he dejado de hacer, el viaje a la locura » («El lector salteado », fragmento 17).

31. C. Liscano, El lenguaje de la soledad, Montevideo, Cal y canto, 2000, p. 35.

32. C. Liscano, "Del caos a la literatura ", Pandora. Répertoire(s) 7/2007, Département d'Études Hispaniques et Hispano-Américaines, Université Paris 8; El Eco, 15.9.2007; Trazas y Ficciones. Literatura y Psicoanálisis, Montevideo, Asociación Psicoanalítica del Uruguay, 2007 ; Revue frictions 13 théâtre-écritures, 2008 (« Du chaos à la littérature »).

33. La traducción es de Jean-Marie Saint Lu.

34. Utiliza una imagen similar de la escritura : « una jabalina en el aire », en su prólogo al libro de la escritora uruguaya Edda Fabbri, Oblivión, Montevideo, Ediciones del caballo perdido, 2007.

35. J.L. Borges, «Pierre Menard, autor del Quijote » en Ficciones, Buenos Aires, Emecé editores, 1958 , p. 56.

36. «El trabajo de contar»: «Me considero con derecho a decir cualquier cosa aunque sea mentira. Aunque yo sepa antes de empezar que es mentira, igual tengo derecho a decirlo [...] Alguna vez, en los ya por demás largos años de mi vida, me he preguntado : ¿ por qué no copiar en lugar de inventar? [...] Para empezar, ¿ es posible contar una historia que nunca haya sido contada? La respuesta, de antiguo conocida, dice que no. Bueno ¿entonces? «(Oficio de ventriloquia 2, 2011, p. 48-50).

37. «nulla dies sine linea » anotó Liscano en la cárcel (« Apuntes : la literatura y la política ») y así se tituló una historieta que publicó en Montevideo, Ediciones del caballo perdido, 2006.

38. En el diario de la cárcel aparece la figura del « lorolector » $(2010$, p. 85$)$ que en el « Diario de El Informante » pasa a ser El Loro Lector. ¿ Cuánto tendrá de protocuervo? 
39. C. F. Moreno en op.cit. (p. XLIII) utiliza la expresión «El escritor a la vista », que es una variante del «trabajo a la vista» utilizado por Macedonio Fernández en los «Papeles de Recienvenido » en la edición Papeles de Recienvenido : Poemas ; relatos ; cuentos ; miscelánea, Buenos Aires, Centro Editor de América Latina, 1966, p. 272

40. J. Prieto, Desencuadernados : vanguardias excéntricas en el Río de la Plata. Macedonio Fernández y Felisberto Hernández, Buenos Aires, Beatriz Viterbo, 2002, p. 74-75.

\section{RESÚMENES}

Este trabajo se pregunta por la manera en que las obras de Macedonio Fernández y Jorge Luis Borges actuaron sobre la literatura última de Carlos Liscano. Después de un primer momento de lectura formadora, estos modelos se vuelven explícitos en los textos Vida del cuervo blanco (2009), «El trabajo de contar» (Oficio de ventriloquia 2, 2011) y «El trabajo de recontar» (2012). Me interesa especificar qué toma Liscano de cada uno de los escritores argentinos y plantear el por qué de esa visibilidad tardía.

Cet article s'interroge sur la manière dont les œuvres de Macedonio Fernández et de Jorge Luis Borges ont agi sur les dernières publications de Carlos Liscano. Après un premier moment de lecture formatrice, ces modèles deviennent explicites dans certains textes comme Vida del cuervo blanco (2009), «El trabajo de contar» (Oficio de ventriloquia 2, 2011) et «El trabajo de recontar » (2012). J'essayerai de montrer ce que Liscano adopte de chacun des écrivains argentins et de proposer une explication sur les raisons de cette visibilité tardive.

This article tries to show how Macedonio Fernández and Jorge Luis Borges' works have influenced Carlos Liscano's literature. After a first stage of formative reading, these models became explicit in Vida del cuervo blanco (2009), «El trabajo de contar " (Oficio de ventriloquia 2, 2011) and «El trabajo de recontar» (2012). I am interested in stating what Liscano took from each of the Argentinean writers and in proposing an explanation on the reasons why they became so obvious only in the last works of Liscano.

\section{ÍNDICE}

Keywords: Carlos Liscano, occasional reader, rewriting, plagiarism

Mots-clés: lecteur inconstant, réécriture, plagiat

Palabras claves: lector salteado, reescritura, plagio

\section{AUTOR}

\section{CARINA BLIXEN}

Universidad Lille 3 